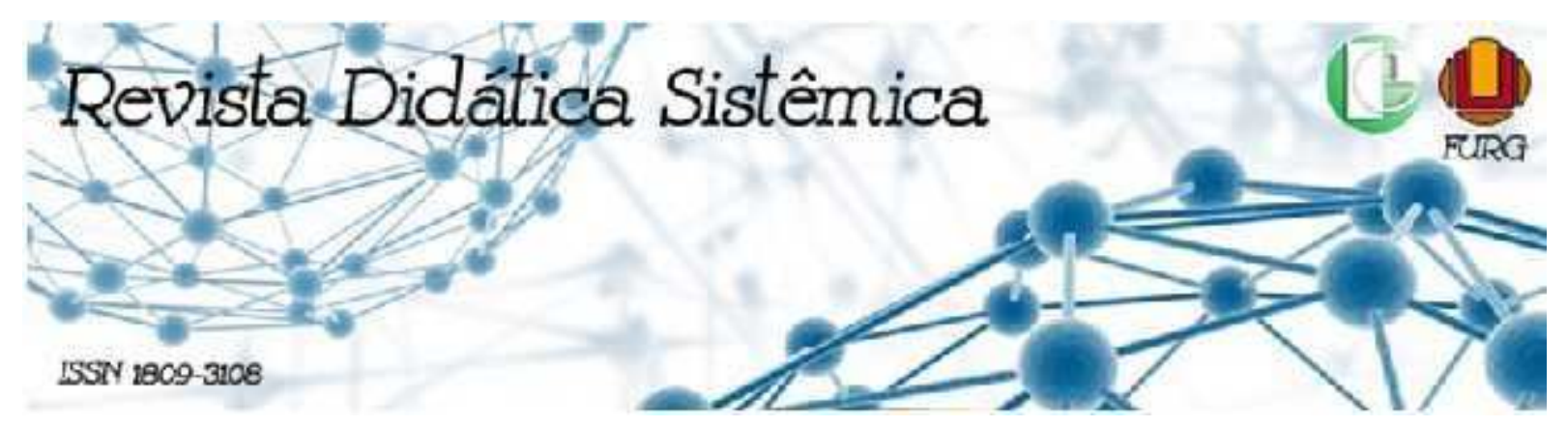

\title{
EDUCAÇÃO FÍSICA NA EDUCAÇÃO INFANTIL: UM BALANÇO DAS DISSERTAÇÕES E TESES DA ÚLTIMA DÉCADA
}

\author{
Leonardo de Carvalho Duarte ${ }^{1}$ \\ Marcos Garcia Neira ${ }^{2}$
}

\begin{abstract}
RESUMO
O artigo analisa as pesquisas no âmbito da Pós-Graduação, realizadas durante a última década (2010 - 2020), com o objetivo de identificar possíveis mudanças paradigmáticas nos estudos mais recentes sobre a Educação Física na Educação Infantil. Para tanto, recorre à Biblioteca Digital de Teses e Dissertações para empreender um gesto descritivo-analítico que permitiu compor o campo e caracterizar a produção acadêmico-científica sobre o tema. A análise de 07 teses de doutorado e de 47 dissertações de mestrado permitiu evidenciar a aproximação da área com referenciais contemporâneos das Ciências Humanas e Sociais, preservando alguma incidência da Psicologia do Desenvolvimento, mas ampliando o diálogo com as teorias curriculares críticas e pós-críticas. Os trabalhos da última década consideram, significativamente, a produção dos estudos sociais da infância, porém ainda persiste o desafio da escuta, participação e coautoria das crianças em pesquisas e práticas pedagógicas da Educação Física na Educação Infantil.
\end{abstract}

Palavras-chave: Educação Física; Educação Infantil; Pesquisas.

\section{PHYSICAL EDUCATION IN CHILDHOOD EDUCATION: A BALANCE OF DISSERTATIONS AND THESES OF THE LAST DECADE}

\begin{abstract}
The article analyzes postgraduate research carried out during the last decade (2010 - 2020), in order to identify possible paradigmatic changes in the most recent studies on Physical Education in Early Childhood Education. To do so, it uses the Digital Library of Theses and Dissertations to undertake a descriptiveanalytical gesture that allowed composing the field and characterizing the academic-scientific production on the subject. The analysis of 07 doctoral theses and 47 master's dissertations allowed to show the approximation of the area with contemporary references of Human and Social Sciences, preserving some incidence of Developmental Psychology, but expanding the dialogue with critical and post-critical curricular theories. The works of the last decade consider significantly the production of childhood social studies, however, the challenge of listening, participating and co-authoring children in research and pedagogical practices of Physical Education in Early Childhood still persists.
\end{abstract}

Keywords: Physical Education; Child education; Researches.

\footnotetext{
${ }^{1}$ Doutor em Educação. Professor Adjunto da Universidade Estadual de Feira de Santana. Integrante dos Grupos de Pesquisa FormarSer/UEFS/CNPq e GPEF/FE-USP/CNPq. E-mail: 1cduarte@uefs.br

${ }^{2}$ Doutor em Educação. Professor Titular da Faculdade de Educação da Universidade de São Paulo. Líder do Grupo de Pesquisas em Educação Física Escolar - GPEF/FE-USP/CNPq. E-mail: $\underline{\text { mgneira@ @usp.br }}$
} 


\section{EDUCACIÓN FÍSICA EN LA INFANCIA EDUCATION: UN EQUILIBRIO DE DISERTACIONES Y TESIS DE LA ÚLTIMA DÉCADA}

\section{RESUMEN}

El artículo analiza las investigaciones de posgrado realizadas durante la última década (2010 - 2020), con el fin de identificar posibles cambios paradigmáticos en los estudios más recientes sobre Educación Física en Educación Infantil. Para ello, utiliza la Biblioteca Digital de Tesis y Disertaciones para emprender un gesto descriptivo-analítico que permitió componer el campo y caracterizar la producción académico-científica sobre el tema. El análisis de 07 tesis doctorales y 47 disertaciones de maestría permitió mostrar la aproximación del área con referentes contemporáneos de las Ciencias Humanas y Sociales, preservando cierta incidencia de la Psicología del Desarrollo, pero ampliando el diálogo con teorías curriculares críticas y poscríticas. Los trabajos de la última década consideran de manera significativa la producción de estudios sociales infantiles, sin embargo, aún persiste el desafío de escuchar, participar y co-autorizar a los niños en las investigaciones y prácticas pedagógicas de la Educación Física en la Educación Infantil.

Palabras clave: Educación Física; Educación Infantil; Investigaciones.

\section{INTRODUÇÃO}

A partir da promulgação da Lei de Diretrizes e Bases da Educação Nacional - (LDBEN) n 9394/96 (BRASIL, 1996), a Educação Infantil ocupa-se do cuidado e da educação de crianças da faixa-etária de 0 a 5 anos e, legalmente, constitui a primeira etapa da Educação Básica. Além disso, a LDB estabelece, em colaboração com os Estados, o Distrito Federal e os Municípios, as orientações e normas para o desenvolvimento da Educação Infantil. Esse dispositivo legal também chamou a atenção para um tempo-espaço educativo, antes pouco explorado por pesquisadores, mas que, recentemente, vem recebendo atenção.

Quinteiro (2009) considerava que raras são as áreas de conhecimento que priorizam os estudos sobre as crianças, com exceção da Psicologia do Desenvolvimento, e, ainda mais raras, as pesquisas que articulam infância e escola. Buss-Simão (2011) destacou que, no âmbito da educação da pequena infância, tem crescido, no Brasil, o número de produções, mas, relativamente à Educação Física, nessa etapa, o número de trabalhos e experiências divulgadas que poderiam dar sustentação à ação pedagógica é bastante reduzido. Martins et al. (2017) apresentaram um levantamento do tema em sete periódicos, compreendendo o período de 1979 a 2016, e identificaram, entre os 5.720 trabalhos publicados, 117 relacionados à Educação Física na Educação Infantil. Os autores concluíram que "o mapeamento da produção acadêmico-científica indica a consolidação nas duas últimas décadas da Educação Infantil como objeto de estudo nos periódicos da Educação Física" (p. 1074). Tais conclusões evidenciam a 
recente ampliação do interesse da área de Educação Física pelo tema.

A produção acadêmica sobre a Educação Física, no contexto da Educação Infantil, é marcada por práticas hegemonicamente pautadas pela historicidade higienista e esportivista, bem como por propostas "desenvolvimentistas" e "psicomotoras", como atestam os trabalhos de Sayão (1999, 2002), Richter e Vaz (2010), Mello e Santos (2012) e Martins (2015 e 2018). Em levantamento mais recente apresentado por Farias et al. (2019), os/as autores/as consideraram que a Educação Física na Educação infantil,

vive um momento ímpar [...] o número de pesquisas que vêm abordando essa temática cresceu consideravelmente nas últimas décadas, sendo ainda possível notar estudos que vêm tratando de outras temáticas que vão além do ensino dos aspectos motores e da aptidão física nessa etapa da Educação Básica. (p. 14)

Esse cenário nos provocou a investigar a produção das pesquisas no âmbito da Pós-

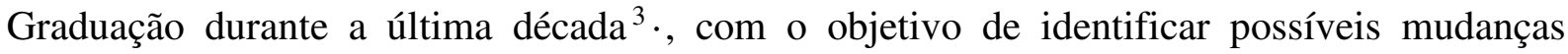
paradigmáticas na produção discursiva mais recente sobre a Educação Física na Educação Infantil. Para tanto, recorremos à Biblioteca Digital de Teses e Dissertações para empreender um gesto descritivo-analítico que nos permitisse, minimamente, compor o campo e reconhecer algumas características, presenças, ausências e tensões veiculadas nas produções acadêmicocientíficas sobre o tema.

\section{PRODUÇÕES NA BDTD (2010-2020)}

A Biblioteca Digital Brasileira de Teses e Dissertações (BDTD) integra e dissemina, em um só portal de busca, os textos completos das teses e dissertações defendidas nas Instituições brasileiras de ensino e pesquisa. $\mathrm{O}$ acesso a essa produção científica é livre de quaisquer custos. Acessamos a plataforma em duas etapas, a primeira, em agosto de 2018, através do endereço http://bdtd.ibict.br/vufind/. Nele, identificamos o acesso para "busca avançada" em que procedemos à pesquisa utilizando os descritores "Educação Física"; "Educação Infantil"; "Educação Física Infantil”; "Infância”; "Pré-Escola”, "Cultura Corporal”; "currículo cultural”. Também, empregamos diferentes combinações entre os descritores, considerando "todos os

\footnotetext{
${ }^{3}$ Por definição, uma década é um período de dez anos. O início e fim dependem de interpretação e do uso cultural, mas não há uniformidade na questão de início e fim da década. Nosso recorte considerou o período compreendido entre janeiro de 2010 e setembro de 2020, que totaliza 10 anos e 8 meses. Assim, optamos por utilizar o termo por considerar adequado e mais expressivo.
} 
campos" e "todos os termos", mas utilizando como filtro o ano de defesa entre 2010 e 2018. Em setembro de 2020, realizamos uma segunda varredura repetindo os descritores e, dessa vez, utilizamos o filtro do ano de defesa 2018 a 2020 a fim de atualizar os registros e abranger a totalidade do período pretendido. Obtivemos os resultados brutos conforme os quadros 01 e 02 .

Quadro 01 - Resultado de busca em BDTD em agosto de 2018, e filtro "ano 2010 e 2018"

\begin{tabular}{|c|c|c|c|}
\hline Descritor 1 & Descritor 2 & Descritor 3 & Resultado \\
\hline "Educação Física" & "Educação Infantil" & ------------------- & 61 \\
\hline "Educação Física" & "currículo cultural" & "Educação Infantil" & 00 \\
\hline "Educação Física" & Infância & ------------------- & 121 \\
\hline "Educação Física" & Pré-Escola & ----------------- & 17 \\
\hline "cultura corporal" & "Educação Infantil" & ------------- & 07 \\
\hline "cultura corporal" & Infância & ---------- & 05 \\
\hline "Educação Física Infantil" & ------------------ & ----------- & 04 \\
\hline
\end{tabular}

Fonte: elaborada pelos autores.

Quadro 02 - Resultado de busca em BDTD em setembro de 2020 e filtro "ano 2018 e 2020"

\begin{tabular}{|c|c|c|c|}
\hline Descritor 1 & Descritor 2 & Descritor 3 & Resultado \\
\hline "Educação Física" & "Educação Infantil" & ------------------- & 30 \\
\hline "Educação Física" & "currículo cultural" & "Educação Infantil" & 00 \\
\hline "Educação Física" & Infância & ------------------- & 42 \\
\hline "Educação Física" & Pré-Escola & -------------------- & 05 \\
\hline "cultura corporal" & "Educação Infantil" & -------------- & 02 \\
\hline "cultura corporal" & Infância & -------------- & 04 \\
\hline "Educação Física Infantil" & ---------------- & -------- & 05 \\
\hline
\end{tabular}

Fonte: elaborada pelos autores.

Utilizamos o recurso Export CSV do site e exportamos os resultados brutos, gerando planilhas em Excel que foram amplamente exploradas. Inicialmente, fizemos a leitura do título, resumo e palavras-chave para aplicar critérios de inclusão, a saber: 1) trabalhos, exclusivamente, da Educação Infantil, primeira etapa da Educação Básica; 2) trabalhos desenvolvidos em contextos formais de ensino; 3) articulação da Educação Infantil com Educação Física ou com a cultura corporal; 4) discussão da Educação Física como componente curricular na Educação Básica. Os estudos que não atendiam a esses critérios foram excluídos. Em alguns casos, foi necessário realizarmos a leitura da introdução e de partes metodológicas para confirmá-los ou excluí-los.

Os procedimentos permitiram identificar 54 textos: 07 teses de doutorado e 47 dissertações de mestrado. A análise levou à composição de um cenário das publicações, o qual passamos a apresentar. 
Gráfico 01 - Ano de defesa dos trabalhos encontrados na BDTD

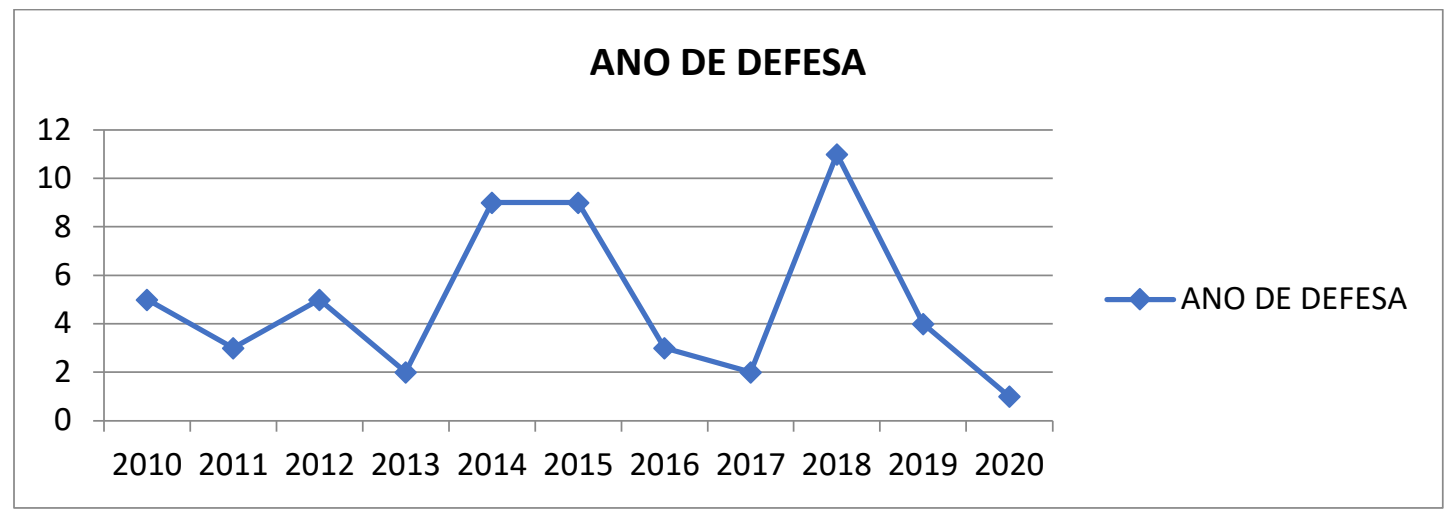

Fonte: Produzido pelos autores.

Conforme podemos ler no gráfico 01, os anos de maior produção foram 2018, com 11 trabalhos, 2014 e 2015, com 09 trabalhos defendidos. Martins (2018), em levantamento anterior, que compreendeu os anos de 1979 e 2016, identificou que 2012 e 2014 foram os anos que tiveram maior número de artigos publicados. Se tomarmos como referência a tendência cada vez maior de incentivo e indução à divulgação dos resultados dos trabalhos acadêmicos no formato de artigos, parece haver correspondência entre os anos com mais trabalhos defendidos e os anos com mais trabalhos publicados em periódicos científicos.

Gráfico 02 - Instituições onde os trabalhos encontrados na BDTD foram realizados

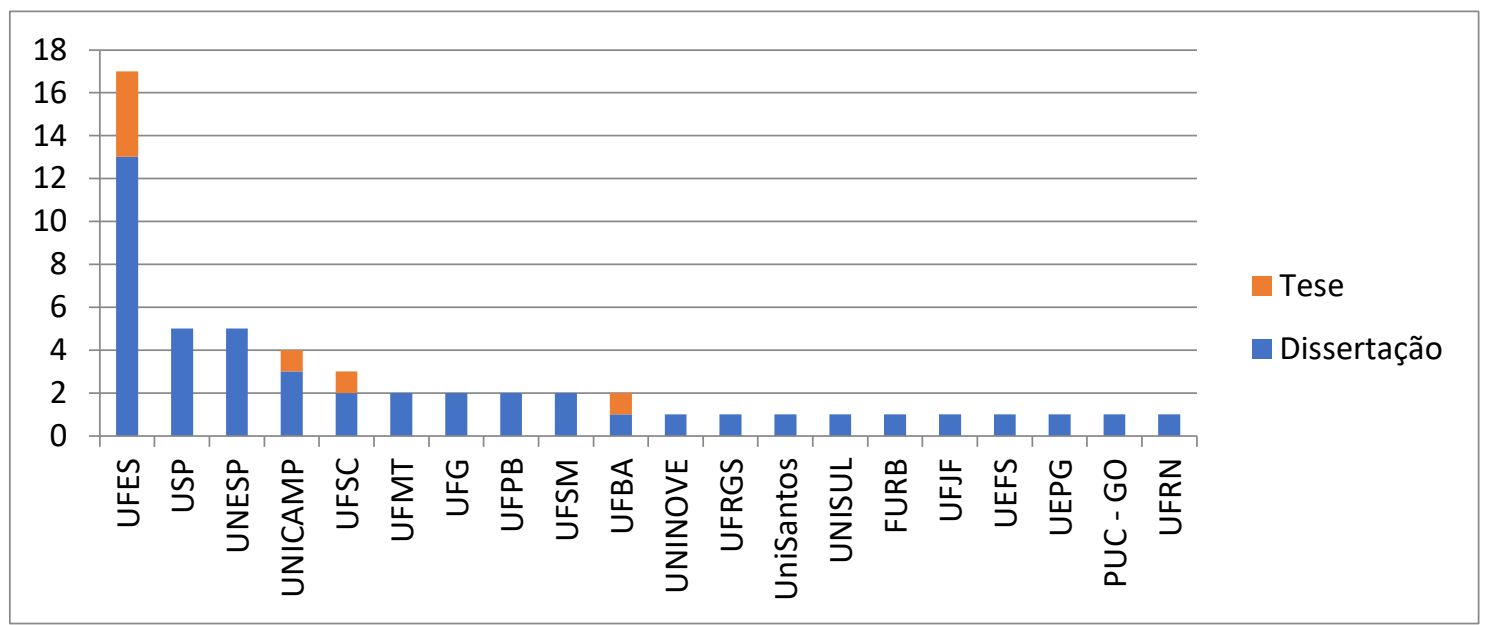

Fonte: Produzido pelos autores.

Ao visualizar o gráfico 02 , em que relacionamos as Instituições onde os trabalhos encontrados na BDTD foram produzidos, percebemos o destacado papel da Universidade Federal do Espírito Santo, que concentra 13 dissertações e 4 teses defendidas entre 2010 e 2020, 
assim como fica evidente a vantagem do Estado de São Paulo em virtude do maior número de Programas de Pós-Graduação. Esses elementos também foram destacados nas avaliações anteriores realizadas por Martins (2018) e Farias et al (2019), ou seja, as regiões Sudeste e Sul têm maior quantidade de trabalhos, e os Estados de São Paulo, Espirito Santo e Santa Catarina despontam na produção sobre a temática.

Gráfico 3 - Áreas dos Programas onde os trabalhos encontrados na BDTD foram realizados

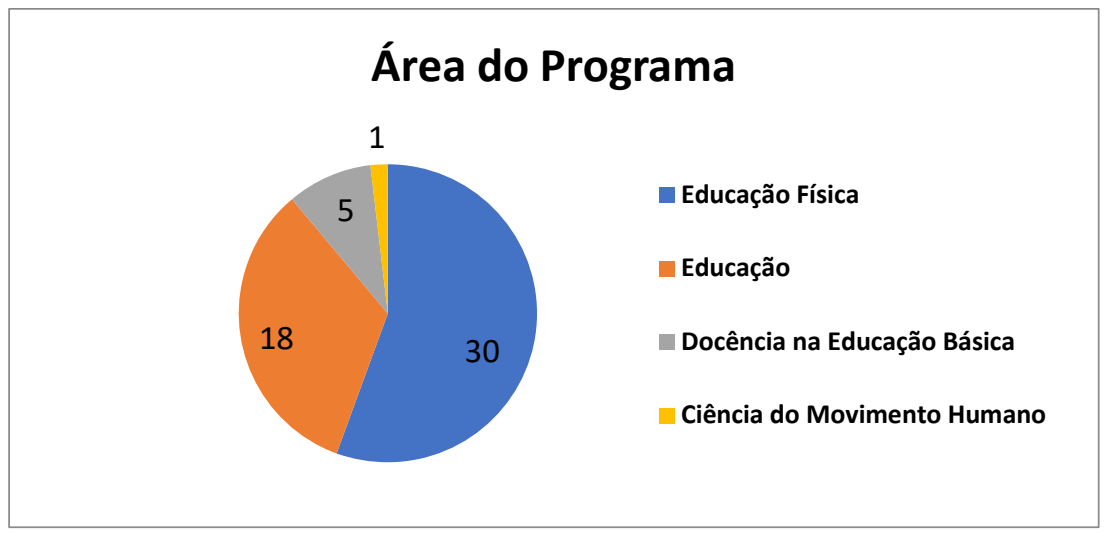

Fonte: Produzido pelos autores

O gráfico 03 evidencia que a maioria dos trabalhos (30) foi realizada em Programas de Pós-Graduação em Educação Física, seguindo-se por número significativo de trabalhos (18) desenvolvidos em Programas de Pós-Graduação em Educação. Apenas um trabalho em programa de Ciência do Movimento Humano e cinco trabalhos mais recentes, realizados em Programas de Mestrado Profissional em Docência na Educação Básica. Das sete teses defendidas, cinco foram em programas de Educação Física e duas, em Educação. Do ponto de vista do maior quantitativo de produções vinculadas a programas de Educação Física, o resultado converge com o anunciado por Farias et al (2019), entretanto, esses autores identificaram um número muito superior de teses na área de Educação, diferindo do nosso resultado.

Um montante de $53^{4}$ pessoas assinam os 54 trabalhos analisados. Se observarmos apenas os nomes, segundo a tradição, 40 são comuns ao gênero feminino, enquanto 13, ao masculino. Entre as 7 teses, 5 são de autores com nomes de tradição masculina e 2 de tradição feminina, e, entre as 47 dissertações, 8 masculinos e 39 femininos. Constatamos que a produção acadêmica mais recente sobre a temática é hegemonicamente feminina.

As pesquisas foram orientadas por 33 docentes, e 18 têm nomes tradicionalmente

\footnotetext{
${ }^{4}$ Rodrigo Lema Del Rio Martins tem duas produções, 2015, dissertação; 2018, tese.
} 
vinculados ao gênero feminino, enquanto 15, ao masculino. Entretanto, professores ainda orientaram mais trabalhos (31) enquanto professoras orientaram menos (23), mas isso se deve, exclusivamente, à atuação destacada do professor André da Silva Mello da UFES, que, na última década, acumulou 10 orientações vinculadas ao tema, seguido, de muito longe, pelas professoras Zenólia Figueiredo também da UFES e Dagmar Aparecida Hunger da UNESP, ambas com 3 orientações; a primeira, no começo da década e a segunda de trabalhos mais recentes ligados ao mestrado profissional. Nesse aspecto, nossos resultados corroboram com Silva (2018) e Martins (2018) apenas quanto ao nome de André da Silva Mello, ao menos quanto à orientação das pesquisas acadêmicas em Programas de Pós-Graduação. Nosso recorte, nas produções mais recentes, não nos permite apontar outros pesquisadores com tamanha implicação com a temática da EF na EI na atualidade.

Gráfico 04 - Gênero dos autores de acordo com a tradição do nome utilizado - BDTD

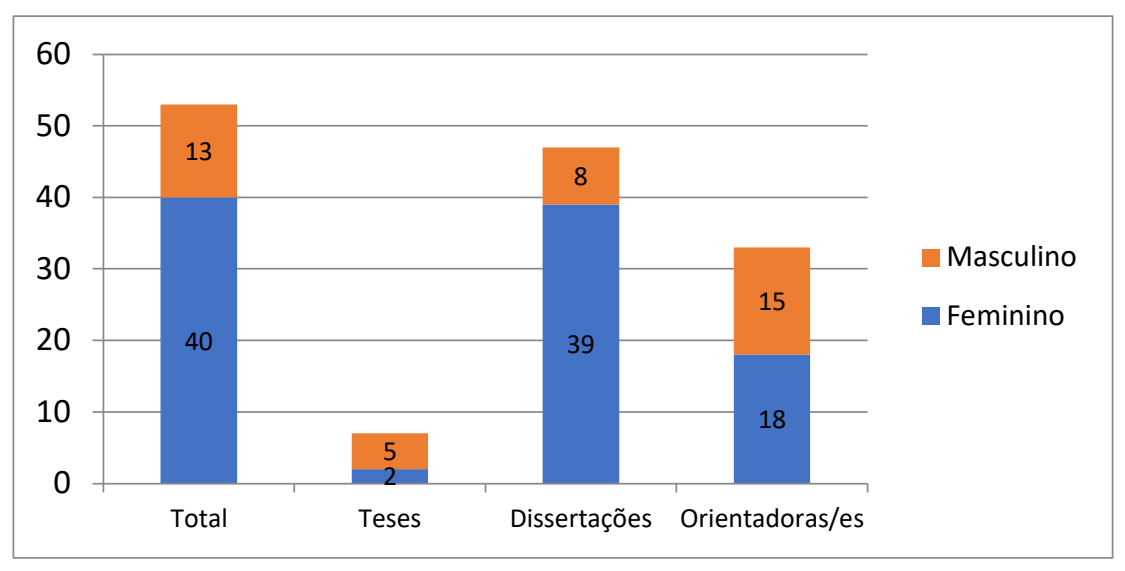

Fonte: Elaborado pelos autores

Quadro 03 - Principais orientadores/as sobre EF na EI na última década (2010 -2020)

\begin{tabular}{|l|c|}
\hline \multicolumn{1}{|c|}{ Professor/a - IES } & N $^{\circ}$ de orientações \\
\hline André da Silva Mello - UFES & 10 \\
\hline Zenólia Christina Campos Figueiredo - UFES & 3 \\
Dagmar Aparecida Cyntia França Hunger - UNESP & \\
\hline Valter Bracht - UFES & \\
Wagner Santos - UFES & \\
Marcos Garcia Neira - USP & 2 \\
Osvaldo Luiz Ferraz - USP & \\
Ademir De Marco - UNICAMP & \\
João Josué da Silva Filho - UFSC & \\
Pierre Normando Gomes-da-Silva - UFPB & \\
Maria Cecília da Silva Camargo - UFSM & \\
\hline
\end{tabular}

Fonte: produzida pelos autores. 
Também, nos interessou saber a área de formação inicial de autoras/es das pesquisas. Para tanto, recorremos à Plataforma Lattes e visualizamos, nos currículos, as graduações declaradas. 37 pessoas possuem graduação em Educação Física; 3, em Pedagogia; 1, em Psicologia; 10 pessoas declaram dois cursos, entre elas, 7 com formação em Educação Física e Pedagogia; 1 Psicologia e Pedagogia; 1 Comunicação Social e Educação Física; 1 Serviço Social e Educação Física e 2 não tiveram o currículo localizado. Esses dados evidenciam que a produção se dá, basicamente, no campo da Educação Física, seguido da Pedagogia. Certamente, a combinação dos descritores influenciou esse resultado. Alterações, nos termos de busca, poderão apontar outras configurações.

Gráfico 05 - Formação inicial de autoras/es declarada em Currículo Lattes

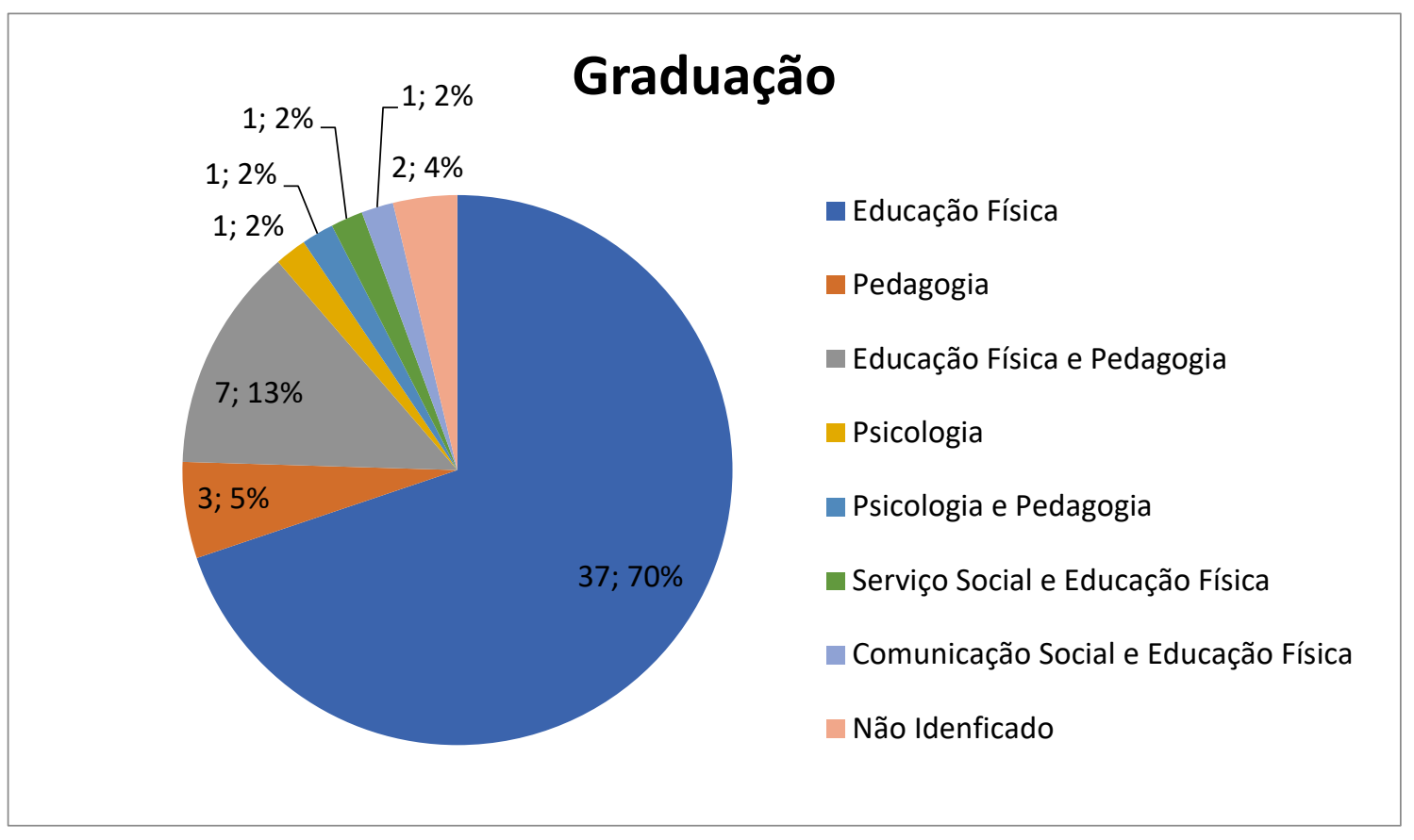

Fonte: Produzido pelos autores.

No que concerne ao conteúdo dos trabalhos, há uma grande diversidade teóricometodológica, convergindo com a conclusão dos estudos de Martins (2018), Farias et al (2019). No escopo do nosso levantamento, encontramos pesquisas bibliográficas, documentais, etnografias, pesquisas-ação, estudos de caso e outros. Do ponto de vista da abordagem, a totalidade dos trabalhos assumiu abordagem qualitativa; alguns conciliaram análises quantitativas com a dimensão qualitativa. Os instrumentos também foram os mais variados, incluindo questionários, entrevistas, observações, fotografias, filmagens, entre outros, também coincidindo com o que fora identificado por Farias et al (2019). 
A respeito do objeto de estudo, é possível indicar que, no período de 2010 a 2020, as pesquisas sobre a Educação Física, na Educação Infantil, refletiram, principalmente, sobre as seguintes questões:

$\checkmark$ Formação de docentes que atuam na Educação Infantil.

$\checkmark$ Inserção da Educação Física na Educação Infantil.

$\checkmark$ Práticas pedagógicas da Educação Física na Educação Infantil.

$\checkmark$ Representações e concepções de criança, infância, Educação Física e Educação Infantil.

$\checkmark$ Propostas e Programas para o desenvolvimento da Educação Física na Educação Infantil.

$\checkmark$ Questões de gênero, Educação Física e Educação Infantil.

As temáticas foram discutidas a partir de aportes teóricos distintos, mas ficou evidente maior aproximação da produção com o campo das Ciências Humanas e Sociais. Isso pode ser reflexo do grande número de trabalhos realizados em programas de Educação e da grande maioria das pesquisas realizadas em Programas de Educação Física estar vinculada a áreas de concentração, tais como: estudos Pedagógicos e Socioculturais da Educação Física; Educação Física e Sociedade; Fundamentos Pedagógicos e Sócio antropológicos do Corpo; Cultura, Educação e Movimento Humano, entre outras.

Em pesquisa anterior, Martins (2018) tratou da relação da Educação Física com a Educação Infantil, abarcando diferentes fontes, entre elas: os documentos legais e pedagógicos da Educação Infantil; as produções acadêmico-científicas (artigos, teses, dissertações e comunicações de evento) na área de Educação Física; os currículos de formação de professores de Educação Física de universidades públicas do país; e representações de docentes de Educação Física que atuam em redes públicas de capitais brasileiras. Em suas considerações, destacou que

O cenário apresentado aponta para a expansão da presença da Educação Física na Educação Infantil e ao mesmo tempo sinaliza práticas pedagógicas desse componente curricular que não consideram a centralidade da criança e o seu protagonismo, distantes, portanto, das atuais orientações legais e pedagógicas que balizam o trabalho educativo a ser desenvolvido pelas instituições dedicadas a cuidar/educar crianças de zero a cinco anos de idade. (p. 35) 
O autor constatou que grande parte da produção acadêmico-científica da Educação Física, na Educação Infantil, se vincula aos pressupostos da Psicomotricidade e do Comportamento Motor, e que "as crianças ocupam uma posição de passividade na mediação pedagógica com o conhecimento" (MARTINS, 2018, p. 156). Além disso, denunciou a divergência desses resultados das concepções presentes nos documentos legais e pedagógicos recentes, como as DCNEI e a BNCC, que se ancoram em contribuições da Sociologia da Infância, e concebem as crianças como atores sociais, sujeitos de direitos e produtoras de cultura.

O estudo de Farias et al (2019, p. 15) segue o mesmo rastro:

[...] a complexidade do contexto escolar e, principalmente, a inserção da EF na EI tem se mostrado um grande desafio para os(as) professores(as) do componente, além da dificuldade de efetivar práticas pedagógicas que voltem seus olhares para os aspectos culturais e da sociologia bem como considerem as crianças da EI como seres históricos e sociais. [...] Embora tenhamos encontrado trabalhos que avançaram nesse sentido, entendemos que ainda é necessário materializar em formato científico mais estudos que nos mostrem como os(as) professores(as) de EF vêm propondo tais ações pedagógicas na realidade da EI.

Em sentido distinto, percebemos que a interlocução com a Sociologia, Pedagogia, Filosofia e História fazem frente à Psicologia e ao Desenvolvimento Motor, no escopo da nossa seleção. Isso aponta para a possibilidade de superação da hegemonia histórica que as ciências biomédicas exerceram sobre a Educação Física, especialmente, na Educação Infantil. E consequentemente, de concepções mecanicistas e biologicistas da criança e da Educação Infantil. Identificamos número significativo de trabalhos recentes recorrendo às teorias críticas, especialmente, à concepção crítico-superadora. Contudo, o diálogo com a teorização curricular pós-crítica, sobretudo, na perspectiva pós-estrutural e pós-colonial, ainda é bastante restrito.

Percebemos menor presença da temática étnico-racial, da negritude e das africanidades atravessando as pesquisas sobre a EF na EI. Apenas duas pesquisas (DOURADO SILVA, 2013; MARTINS, 2015) trouxeram a capoeira para a cena, mesmo assim uma delas como conteúdo de um programa de atividades motoras para as crianças de 3 a 6 anos. Isso pode apenas refletir os limites das nossas leituras, mas também ser consequência do distanciamento das "Epistemologias do Sul" (SANTOS; MENESES, 2010), referenciais pós-coloniais, decoloniais, bem como do apagamento histórico dos saberes pretos, quilombolas e indígenas em decorrência do racismo estrutural que nos constitui socialmente. 
As pesquisas sobre formação de docentes, para a atuação na Educação Infantil, se dirigiram, especialmente, à formação inicial em Educação Física, discutida pelos documentos legais, currículos, projetos, programas, ementas de disciplinas e concepções de professores formadores (GOMES, 2012, DUDECK, 2014; LACERDA, 2014; MARTINS 2015, 2018; MACHADO, 2019), e à formação continuada de docentes (Educação Física e Pedagogia), auxiliares e gestores. (FRANCELINO, 2010; MATOS, 2015; LEITE, 2010; FIGUEIRA, 2014). Entre encontros, desencontros, fragilidades e potencialidades, não há desacordo quanto à necessidade de investimentos e implicação com os processos de formação. $O$ tema também reverberou em pesquisas que analisaram a inserção da Educação Física na Educação Infantil e experiências e práticas dirigidas à cultura corporal, corpo e movimento, que reconheceram "fragilidades" nas ações pedagógicas e apontaram como imperativa a formação (MACEDO, 2010; SOUZA, 2012; RECCO, 2014; SCOTTÁ, 2018; PEREIRA, 2020). Se há um consenso possível entre as pesquisas, é a necessidade de continuarmos investindo na formação docente.

A inserção da Educação Física, na Educação Infantil, também foi objeto de várias pesquisas (GONZAGA, 2011; ROCHA, 2011; JESUS, 2014; RODRIGUES, 2015; QUARANTA, 2015; FREIRE, 2018; MARTINS, 2018). A presença do professor de Educação Física vem se estabelecendo em muitos municípios brasileiros, mas diferentes análises apontam "dilemas" e "dificuldades" na atuação com os bebês e com crianças pequenas. Entretanto, também, há apontamentos quanto às limitações da atuação de professoras polivalentes e auxiliares no tratamento pedagógico da cultura corporal. A maioria dos discursos aponta na direção de práticas integradas entre os profissionais, mas isso ainda não vem sendo amplamente observado. Do nosso ponto de vista, não há possibilidade fora das ações coletivas e colaborativas definidas e produzidas nos contextos educacionais. (NEIRA, 2008, 2009; DUARTE, 2021).

Três pesquisas articulam a temática da Educação Física, na Educação Infantil, com questões de gênero. Os trabalhos evidenciam a importância da ação docente e das relações que ocorrem nas escolas para reprodução e/ou superação das normas de gênero e de práticas sexistas (MARIANO, 2010; MARTINS, 2014). Jogos, brinquedos e brincadeiras foram utilizados para problematizar gênero (MARTINS, 2014) ou analisados e apontados como práticas que tendem a corroborar com a reprodução de papéis de masculinidade e feminilidades normativas (GODOY, 2017).

Pesquisas com o foco nas representações sociais sobre a atuação de professores/as de Educação Física, na Educação Infantil, apontam que docentes apresentam dificuldades de 
definir seu papel pedagógico na EI (MATTOS, 2012) ou que parcela significativa enuncia representações sociais negativas sobre a Educação Infantil (JESUS, 2014). Aquelas que se debruçaram sobre concepções de criança e infância, em documentos curriculares oficiais nacionais ou de municípios específicos, mencionam tanto a apropriação das concepções prescritas (MOREIRA, 2012) quanto a desarticulação das orientações e concepções anunciadas e práticas pedagógicas observadas (ROCHA, 2014; HENING, 2014).

Enquanto a concepção de cultura corporal de documentos como RCNEI, DCNEI e PNEI foi criticada e considerada biologicista (DIAS, 2015), as noções de corpo e movimento da BNCC foram consideradas "inscritas num contexto cultural e distantes de uma ideia estereotipada e biologicista" (MARTINS, 2018, p.60).

As pesquisas que investigaram práticas pedagógicas da Educação Física, na Educação Infantil, foram maioria (aproximadamente 32\%). Nelas, encontramos um conjunto de experiências realizadas por professoras e professores com análises, reflexões e proposições para as atividades da "Educação Física", "cultura corporal", "eixo corpo e movimento" com bebês e crianças pequenas. A partir delas, pudemos perceber preocupações com aspectos gerais das práticas, como também, de específicos, por exemplo, os saberes docentes (PERINI, 2016), o jogo (KLIPPEL, 2013), as produções culturais das crianças (ZANDOMINEQUE, 2018; SCOTTÁ, 2018) e a avaliação (LANO, 2019).

Olhando o conjunto de pesquisas que se empenharam em apresentar propostas de ensino, orientações e programas para a Educação Física na Educação Infantil, percebemos diferentes concepções teórico-conceituais, com destaque para proposições vinculadas à teoria histórico-cultural. Entretanto, dos cinco trabalhos que fizeram essa defesa, apenas um considerou as crianças como sujeitos de pesquisa (FERREIRA, 2010), os demais se basearam em reflexões teóricas (TEIXEIRA, 2018), ou da interação de pesquisadores com professores/as (SANTOS, 2016; MARTINS, 2019; LIMA, 2019).

É importante frisar que algumas dissertações e teses que consideramos estar mais focadas, na prática pedagógica, não se furtaram a fazer anúncios propositivos para a Educação Física na Educação Infantil. Por exemplo, grande parte das pesquisas realizadas na UFES, no âmbito do Núcleo de Aprendizagem com a Infância e seus Fazeres (NAIF), fazem conexões teórico-conceituais entre a Sociologia da Infância e os Estudos com o cotidiano. Uma "síntese integradora" para a constituição de uma perspectiva pedagógica não sistematizada para a intervenção da Educação Física na Educação Infantil, proposta por Assis (2015), resulta do diálogo com parte desses trabalhos. 
Os trabalhos consideram, significativamente, a produção dos estudos sociais da infância e a defesa da agência das crianças na produção e na reprodução da cultura e dos seus modos de vida, contudo, ouvi-las, considerá-las sujeitos, participantes e/ou coautoras nas pesquisas ainda é um desafio. A maioria dos trabalhos considerou professores e/ou documentos enquanto poucos trabalhos consideraram as crianças como informantes/sujeitos nas investigações. Em nossa interação com os textos, reconhecemos a participação das crianças em apenas 18, contudo, dentre esses, também incluímos aqueles em que as crianças apenas se envolveram em "testes motores" (LOBO, 2017), "experimentos didáticos" (FERREIRA, 2010; DOURADO SILVA, 2013) e/ou "programas de jogos" (ARAÚJO, 2018), considerando que nem sempre tiveram suas percepções, ideias, opiniões, desejos e/ou vozes consideradas.

\section{CONSIDERAÇÕES FINAIS}

A análise realizada permitiu evidenciar a aproximação da área com referenciais contemporâneos das Ciências Humanas e Sociais, mas ainda com limitações das teorias póscríticas, sobretudo, nas perspectivas pós-estruturais e pós-coloniais. Os estudos mais recentes passam a considerar significativamente a produção dos estudos sociais da infância e a defesa da agência das crianças na produção e na reprodução da cultura e dos seus modos de vida, contudo ouvi-las, considerá-las sujeitos, participantes e/ou coautoras em pesquisas e nas práticas pedagógicas ainda é um desafio.

Reconhecemos que as características e discussões que priorizamos podem ser consideradas arbitrárias, contudo, ao adotarmos um gesto descritivo-analítico, nosso interesse residiu em, minimamente, compor o campo e reconhecer algumas características, presenças, ausências e tensões veiculadas nas produções acadêmico-científicas identificadas - as quais, por estarem circunscritas por descritores, período e critérios de inclusão, podem somente refletir uma imagem, com mais ou menos foco, que se junta às outras produzidas (no passado e no futuro) para, também, "pôr luz" sobre o cenário da Educação Física na Educação Infantil. 


\section{REFERÊNCIAS}

ARAÚJO. Kelly Cristina Alves de. Jogos tradicionais e percepção ecológica das cores nas aulas de Educação Física. 2018. 94f. Dissertação (Mestrado em Educação Física) Programa Associado de PósGraduação em Educação Física Universidade de Pernambuco e Universidade Federal da Paraíba. João Pessoa, 2018.

ASSIS, Lívia Carvalho de. Por uma perspectiva pedagógica para intervenção da Educação Física com a EI. 2015. 181f. Dissertação (Mestrado em Educação Física) - Universidade Federal do Espírito Santo, Centro de Educação Física e Desportos. Vitória, 2015.

BRASIL. Lei 9.394 de 20 de dezembro de 1996. Estabelece as diretrizes e bases da educação nacional. Brasília, 1996.

BUSS-SIMÃO. Marcia. Educação física na educação infantil: compartilhando olhares e construindo saberes entre a teoria e a prática. Cadernos de Formação RBCE, p. 9-21, jan. 2011.

DIAS, Roseane Suzart Leite. Crítica da concepção de criança, de educação e de cultura corporal na educação infantil: análise dos documentos oficiais. 2015. 120 f. Dissertação (Mestrado em Educação) - Universidade Estadual de Feira de Santana, Programa de Pós-Graduação em Educação. Feira de Santana, 2015.

DOURADO SILVA, Lucas Contador. Proposta pedagógica da capoeira na educação infantil. 2013. 199f. Dissertação (Mestrado em Educação Física) Universidade Estadual de Campinas, Faculdade de Educação Física. Campinas, 2013.

DUARTE, Leonardo de Carvalho. Educação Física Cultural na Educação Infantil: imagensnarrativas produzidas com professoras e crianças nos/dos/com os cotidianos de uma EMEI paulistana. 2021. 384f. Tese (Doutorado em Educação) Universidade de São Paulo, Faculdade de Educação. Programa de Pós-graduação em Educação. São Paulo, 2021.

DUDECK, Tamara Suellen. Educação física escolar na educação infantil: a formação em questão. 2014. 275f. Dissertação (Mestrado em Educação Física) Universidade Federal do Mato Grosso, Faculdade de Educação Física, Programa de Pós-graduação em Educação Física, Cuiabá, 2014.

FARIAS. Uirá de Siqueira et al. Análise da produção do conhecimento sobre a Educação Física na Educação Infantil. Movimento, Porto Alegre, v. 25, e25058, 2019.

FERREIRA, Maria Clemência Pinheiro de Lima. Educação física na educação infantil: ensino do conceito de movimento corporal na perspectiva histórico-cultural de Davydov. 2010. 168f. Dissertação (Mestrado em Educação) Pontifícia Universidade Católica de Goiás, UniEVANGÉLICA, Centro Universitário de Anápolis, 2010.

FIGUEIRA, Natalia Tazinazzo. O parque como espaço educativo: práticas corporais num projeto de formação de professoras para educação infantil. 2014. 177f. Dissertação (Mestrado em Educação). Universidade de São Paulo, Faculdade de Educação, Programa de Pós-graduação em Educação. São Paulo, 2014.

FRANCELINO, Kenia dos Santos. A docência em educação física na educação infantil: a (re)construção de práticas de formação continuada. 2010. 105 f. Dissertação (Mestrado em Educação Física) - Universidade Federal do Espírito Santo, Centro de Educação Física e Desportos, 2015.

FREIRE, Erika Janaina Santiago Moreira. A presença dos conhecimentos de educação física no Núcleo de Educação da Infância da Universidade Federal do Rio Grande do Norte. 2018. 117f. Dissertação (Mestrado em Educação Física) Universidade Federal do Rio Grande do Norte, Centro de Ciências da Saúde, Programa de Pós-graduação em Educação Física, Natal, 2018.

GODOY, Karine Natalie Barra. Construção das identidades de gênero na infância: os discursos dos brinquedos e brincadeiras. 2017. 163f. Dissertação (Mestrado em Educação Física) - Universidade Federal de Juiz de Fora, Universidade Federal de Viçosa, Faculdade de Educação Física, Programa de Pós-graduação em Educação Física, Juiz de Fora, 2017. 
GOMES, Manoel dos Santos. Educação física na educação infantil: um estudo sobre a formação de professores em educação física. 2012. 243f. Tese (Doutorado em Educação) - Universidade Federal de Santa Catarina, Centro de Ciências da Educação. Programa de Pós-Graduação em Educação.

Florianópolis, 2012.

GONZAGA, Laerson Pires. Educação corporal para as crianças pequenas: existe lugar para a educação física? 2011. 151 f. Dissertação (Mestrado em Educação) - Universidade Federal de Goiás, Faculdade de Educação, Goiânia, 2011.

HENNING, Geovana Alzira Hillesheim. A educação física e a infância: as crianças da pré-escola inseridas nas escolas de ensino fundamental em Blumenau, SC. 2014. 163f. Dissertação (Mestrado em Educação). Universidade Regional de Blumenau, Programa de Pós-graduação em Educação. Blumenau, 2014.

JESUS, Joíse Fernandes de. Representações sociais de professores sobre a inserção/intervenção pedagógica da educação física na educação infantil de Serra. 2014. 124f. Dissertação (Mestrado em Educação Física) - Universidade Federal do Espírito Santo, Centro de Educação Física e Desportos. Vitória, 2014.

KLIPPEL, Marcos Vinicius. O jogo na educação física da educação infantil: usos e apropriações em um CMEI de Vitória/ES. 2013. 151f. Dissertação (Mestrado em Educação Física) - Universidade Federal do Espírito Santo, Centro de Educação Física e Desportos. Vitória, 2013.

LACERDA, Cristiane Guimarães de. Formação de professores de Educação Física para Educação Infantil na perspectiva da formação ampliada: contribuições da pedagogia histórico critica. 2014. 127f. Dissertação (Mestrado em Educação) Universidade Federal da Bahia, Faculdade de Educação, Programa de Pós-Graduação em Educação. Salvador, 2014.

LANO, Marciel Barcelos. Usos da avaliação indiciária na educação física com a educação infantil. 2019.148f. Tese (Doutorado em Educação Física) - Universidade Federal do Espírito Santo, Programa de Pós-Graduação em Educação Física, Vitória, 2019.

LEITE, Ana Maria. Caixa de brinquedos e brincadeiras: uma aliada na construção de atitude lúdica para a ressignificação da prática pedagógica do movimento na educação infantil. 2010, $153 \mathrm{f}$.

Dissertação (Mestrado em Educação Física), Escola de Educação Física e Esporte da Universidade de São Paulo, São Paulo, 2010.

LIMA. Deivide Telles de. Corpo(s) em movimento na Educação Física Infantil: contribuições na perspectiva da Pedagogia Histórico-Crítica. 2019. 147f. Dissertação (Mestrado Profissional) Universidade Estadual Paulista Júlio de Mesquita Filho - Faculdade de Ciências, Programa de Pósgraduação em Docência para Educação Básica. Bauru, 2019.

LOBO, Leonardo Moreira. Educação Física na educação infantil: influência de uma unidade de ensino de um programa de educação física no desenvolvimento motor dos alunos de uma escola de educação infantil do município de São Paulo. 2017. 53f. Dissertação (Mestrado em Educação Física) Escola de Educação Física e Esporte da Universidade de São Paulo. São Paulo, 2017.

MACEDO Elina Elias. Educação Física na perspectiva cultural: análise de uma experiência na creche. 2010. 134f. Dissertação (Mestrado em Educação) - Faculdade de Educação, Universidade de São Paulo. São Paulo, 2010.

MACHADO, Vanessa Felix. Educação Física, Educação Infantil e Inclusão: repercussões da formação inicial. 2019. 89f. Dissertação (Mestrado em Educação Física) Universidade Federal de Santa Maria. Centro de Educação Física e Desporto. Programa de Pós-graduação em Educação Física. Santa Maria, 2019.

MARIANO, Marina. A educação física na educação infantil e as relações de gênero: educando crianças ou meninos e meninas? / Marina Mariano. - Campinas. 2010. 123f. Dissertação (Mestrado em Educação Física) - Faculdade de Educação Física, Universidade Estadual de Campinas. Campinas, 2010.

MARTINS, Marcelo Salvador. As relações de gênero entre crianças nas brincadeiras. 2014. 62 f. Dissertação (Mestrado em Educação) - Universidade do Sul de Santa Catarina, Programa de Pós- 
graduação em Educação, Tubarão, 2014.

MARTINS, Poliana Carvalho. A organização da educação física na educação infantil no DEI/CEPAE/UFG. 2019. 138 f. Dissertação (Mestrado em Ensino na Educação Básica) - Universidade Federal de Goiás, Goiânia, 2019.

MARTINS, Rodrigo Lema Del Rio. O Pibid e a formação docente em educação física para a educação infantil. 2015. 167 f. Dissertação (Mestrado em Educação Física) - Universidade Federal do Espírito Santo, Centro de Educação Física e Desportos. Vitória, 2015.

MARTINS, Rodrigo Lema Del Rio. O lugar da Educação Física na Educação Infantil. Tese (Doutorado em Educação Física). Centro de Educação Física e Desportos. 2018. 211f. Universidade Federal do Espírito Santo. Programa de Pós-graduação em Educação Física, Vitória, 2018.

MARTINS, Rodrigo Lema Del Rio et al. Mapeamento das produções acadêmico-científicas sobre a Educação Infantil. Anais do XX Congresso Brasileiro de Ciências do Esporte, Goiânia, 2017. Disponível em: http://congressos.cbce.org.br/index.php/conbrace2017/7conice/paper/view/9214 acesso em: 30/05/2018.

MATOS, Nathalia Cristina. A formação continuada e suas contribuições ao professor de educação física da educação infantil de Florianópolis (SC). 2015. 111f. Dissertação (Mestrado em Educação Física) Universidade Federal de Santa Catarina, Centro de Desportos. Programa de Pós-graduação em Educação Física. Florianópolis, 2015.

MATTOS, Aretuza Suzay. As representações de professores de educação física sobre sua docência em creches e núcleos de educação infantil (NEIs). 2012. 122f. Dissertação (Mestrado em Educação) Universidade Nove de Julho - UNINOVE, São Paulo, 2012.

MELLO, André da Silva; SANTOS, Wagner. (Org.). Educação física na educação infantil: práticas pedagógicas no cotidiano escolar. Curitiba: Editora CRV, 2012.

MOREIRA, Priscyla Simões Sousa. Referenciais prescritos para educação infantil: diálogos com o professor de educação física. 2012. 176 f. Dissertação (Mestrado em Educação Física) - Universidade Federal do Espírito Santo, Centro de Educação Física e Desportos. Vitória, 2012.

NEIRA, Marcos Garcia. Educação Física na Educação Infantil: algumas considerações para a elaboração de um currículo coerente com a escola democrática. In: ANDRADE FILHO, N. F. e SCHNEIDER, O. Educação Física para a Educação Infantil: conhecimento e especificidade. São Cristóvão: Editora da UFS, 2008, p. 45-96.

NEIRA, Marcos Garcia. Educação Física na perspectiva cultural: proposições a partir do debate em torno do currículo e da expansão do Ensino Fundamental. Horizontes, Itatiba, v. 27, n. 2, p. 79-89, jul/dez, 2009.

PEREIRA, Ana Claudia da Silva. Diálogos e práticas com a cultura corporal na educação infantil: crianças de zero a três anos. 2020226 f. Dissertação (Mestrado Profissional)-Universidade Estadual Paulista. Faculdade de Ciências, Pós-graduação em Docência para a Educação Básica, Bauru, 2020 PERINI, Rosiléia. A educação física na educação infantil de Serra/ES: os saberes docentes e a prática pedagógica. 2016. 163 f. Dissertação (Mestrado em Educação Física) - Universidade Federal do Espírito Santo, Centro de Educação Física e Desportos. Vitória, 2016.

QUARANTA, Silvia Cinelli. Professores de educação física na educação infantil: dificuldades, dilemas e possibilidades. 2015. 282 f. Dissertação (Mestrado em Educação) - Universidade Católica de Santos, Programa de Mestrado em Educação. Santos, 2015.

QUINTEIRO, Jucirema. Infância e educação no Brasil: um campo de estudos em construção. In: FARIA, Ana Lucia Goulart de; DEMARTINI, Zeila de Brito Fabri; PRADO, Patrícia Dias. (Orgs.). Por uma cultura da infância: metodologias de pesquisa com crianças. Campinas, SP: Autores Associados, 2009. P. 19-47.

RECCO, Kethylin Viotto. O trabalho docente na educação infantil: desafios na relação entre professor de educação física e professor de educação infantil. 2014. 92 f. Dissertação (Mestrado em Educação) - Universidade Estadual Paulista, Instituto de Biociências de Rio Claro, Rio Claro, 2014. 
RICHTER, Ana Cristina; VAZ, Alexandre Fernandez. Educação física, educação do corpo e pequena infância: interfaces e contradições na rotina de uma creche. Movimento, Porto Alegre, v. 16, n. 1, p. 53-70, jan./mar. 2010.

ROCHA, Fioravante Correia. Diferentes infâncias e a prática pedagógica do professor de Educação Física: estudo na rede municipal de Portão/RS. 2014. 167f. Dissertação (Mestrado em Ciências do Movimento Humano) - Universidade Federal do Rio Grande do Sul, Escola de Educação Física, Programa de Pós—graduação em Ciências do movimento humano, Porto Alegre, 2014.

ROCHA, Maria Celeste. Forma escolar, educação física e educação infantil: (im)pertinências. 2011. 135 f. Dissertação (Mestrado em Educação Física) - Universidade Federal do Espírito Santo, Centro de Educação Física e Desportos. Vitória, 2011.

RODRIGUES, Karolina Sarmento. A inserção do professor de educação física na educação infantil no estado do Espírito Santo. 2015. 110f. Dissertação (Mestrado em Educação Física) - Universidade Federal do Espírito Santo, Centro de Educação Física e Desportos. Vitória, 2015.

RODRIGUES, Renata Marques. Construção identitária e processos relacionais de uma professora de educação física em uma instituição de educação infantil. 2012, 124f. Dissertação (Mestrado em Educação Física) Universidade Federal do Espírito Santo, Programa de Pós-Graduação em Educação Física, Vitória, 2012.

SANTOS, Boaventura de Sousa; MENESES, Maria Paula. (orgs). Epistemologias do Sul. São Paulo: Cortez, 2010.

SANTOS, Cristiane Aparecida Silveira dos. Currículo, infância e educação corporal: fundamentos na perspectiva histórico-cultural e orientações curriculares no campo da interdisciplinaridade. 2016. 172 f. Dissertação (Mestrado Profissional)- Universidade Estadual Paulista. Faculdade de Ciências, Programa de Pós-graduação em Docência para a Educação Básica. Bauru, 2016.

SAYÃO, Deborah Thomé. Educação Física na Educação Infantil: riscos, conflitos e controvérsias. Motrivivência, Florianópolis, v. 11, n. 13, p. 221-238, 1999.

SAYÃO, Deborah Thomé. Grupo de estudos em Educação Física na Educação Infantil: alguns aspectos do trabalho pedagógico. Motrivivência, Florianópolis, n. 17, p. 147-158, 2002.

SCOTTÁ, Bianca Andreatta. A valorização das produções culturais das crianças nas mediações pedagógicas do professor de Educação Física na Educação Infantil. 2018. 130f. Dissertação (Mestrado em Educação Física) - Universidade Federal do Espírito Santo, Centro de Educação Física e Desportos.

SILVA, Alessandra Cancenot da. Brincar, corpo e movimento na educação infantil pelo olhar de alguns pesquisadores da educação física. 2018, 86f. Dissertação (Mestrado em Educação Física) Universidade Federal de Santa Maria. Centro de Educação Física e Desporto. Programa de Pósgraduação em Educação Física. Santa Maria, 2018.

SOUZA, Marilia Menezes Nascimento. "Minha história conto eu": multiculturalismo crítico e cultura corporal no currículo da Educação Infantil. 2012. 292f. Dissertação (Mestrado em Educação) Faculdade de Educação, Universidade de São Paulo. São Paulo: 2012.

TEIXEIRA, David Romão. Educação Física na pré-escola: contribuições da abordagem críticosuperadora. - 2018. 156 f. Tese (Doutorado em Educação) - Universidade Federal da Bahia. Faculdade de Educação, Programa de Pós-graduação em Educação, Salvador, 2018.

ZANDOMÍNEGUE, Bethânia Alves Costa. As produções culturais das crianças como eixo de articulação curricular da Educação Física com a Educação Infantil. 2018. 342f. Tese (Doutorado em Educação Física) - Universidade Federal do Espírito Santo, Centro de Educação Física e Desportos. 